\title{
Long-Term Dissolution of Glass Fibers in Water Described by Dissolving Cylinder Zero-Order Kinetic Model: Mass Loss and Radius Reduction
}

https://doi.org/10.1515/chem-2018-0133

received August 16, 2018; accepted October 1, 2018.

\begin{abstract}
Glass fibers are degraded when they are exposed to water. In this work, a model is developed that uses zero-order kinetics for predicting a decreasing glass fiber radius. The model is used to describe experimental test results of almost half a year long-term dissolution of R-glass fibers. The model is able to predict both mass loss and radius reduction kinetics using the same four parameters: initial fiber radius $\left(r_{0}\right)$, rate constants for both short-term degradation $\left(K_{0}^{I}\right)$ and steady-state degradation $\left(K_{0}^{I I}\right)$ and the time when steady-state kinetics are reached $\left(t_{\mathrm{s}}\right)$. All parameters can be easily determined from initial radius measurements and mass loss evolution in time. Elements released and detected during degradation were $\mathrm{Na}, \mathrm{K}, \mathrm{Ca}, \mathrm{Mg}, \mathrm{Fe}, \mathrm{Al}, \mathrm{Si}$ and $\mathrm{Cl}$. Rate constants were obtained for individual ion release and for the total mass loss. The contribution of $\mathrm{Si}$ to the total mass loss was the largest ( $56.1 \%$ by mass). It governed the dissolution process. The kinetics of radius reduction are also reported. The radius reduction was found to be linear with time during the steady-state dissolution. The zero-order kinetic constant and the density of the glass describe the rate (proportionality) of the dissolution.
\end{abstract}

Keywords: glass fibers; model; dissolution; kinetics; ion release.

*Corresponding author: Andrey E. Krauklis, Department of Mechanical and Industrial Engineering, Norwegian University of Science and Technology, 7491 Trondheim, Norway, E-mail: andrejs.krauklis@ntnu.no Andreas T. Echtermeyer: Department of Mechanical and Industrial Engineering, Norwegian University of Science and Technology, 7491 Trondheim, Norway

\section{Introduction}

Glass fibers are widely used as reinforcement in structural composite materials. They are produced from raw materials, which are virtually unlimited in supply [1]. The fibers have high hardness and such desirable reinforcement properties as high strength and stiffness in fiber direction $[1,2]$. It is known that, glass fibers are hydrophilic and are susceptible to a relatively slow degradation when exposed to water environments [3]. Hydrolytic degradation of glass fibers can significantly reduce mechanical strength and leads to corrosion-induced defects [4].

The term degradation is used in the present work to denote all processes which lead to or affect the mass loss of the glass material by interacting with water. This includes the complex nature of several processes occurring in parallel, such as dissolution of glass matrix constituents, gel layer formation, neoformation of solid reaction products, alkaline and alkaline earth ion exchange. Some of these reactions occur while maintaining the glassy state, while others lead to leaching of the reaction products into the water environment [5].

The long-term environmental degradation of glass materials, described by chemical kinetics, has been extensively studied with respect to nuclear waste applications [5,6]. More recently, there has been an increasing interest in environmental degradation of composite laminates, where R-glass is often used as reinforcement [7-10]. However, studies on environmental degradation of composites are usually concerned with deterioration of the mechanical properties, and the kinetics of chemical degradation tend to be overlooked $[8,10]$. A number of studies exist that explain general mechanisms of environmental degradation of glass materials using various approaches that are based on surface reactions, chemical affinity and diffusion [3,1114]. A process-driven approach was described by GeislerWierwille et al., involving the congruent dissolution of the glass coupled to the precipitation and growth of an 
amorphous silica layer at an inwardly moving reaction interface [12]. More recently, a combination of chemical affinity for controlling the distribution of $\mathrm{Si}$ among different alteration phases and the diffusion barrier for the release rate of glass modifiers was implemented by Ma et al. [14]. Dissolution experiments in existing studies are mainly performed with bulk silicate glasses, and fibers are not studied often.

Few studies exist on the kinetics of glass fiber dissolution. Mišíková et al. have studied the E-glass fiber leaching kinetics in distilled water at different temperatures [15]. Bashir et al. studied the kinetics of the dissolution of E-glass fibres in alkaline solutions by immersing single fibers and measuring the diameter change [16]. They concluded that the rate limiting step was either the diffusion of hydroxide ions through the solution or the glass fibre etching itself [16]. Krauklis and Echtermeyer presented a model that predicts Si loss kinetics during long-term hygrothermal aging of fiberreinforced composites [17]. Glass fibers formulated with significant amounts of various metal oxides, such as R-glass (often used in composites), are rarely studied [16]. Thus, this work is concerned with the dissolution kinetics of R-glass fibers in water.

The degradation is divided into two distinct kinetic regions: (1) short-term non-steady-state and (2) long-term steady-state degradation. In the short-term region, the degradation is complex and involves such processes as ion exchange, gel formation and dissolution [5]. When the long-term steady-state is reached, the dissolution becomes dominant $[5,18]$ and the degradation follows zero-order reaction kinetics. Such kinetics depend on the glass surface area in contact with water, which is proportional to the fiber radius. As the dissolution continues, the radius decreases resulting in the mass loss deceleration.

The aim of this work is twofold: (1) to study the longterm dissolution behaviour of R-glass fibers in water and (2) to develop a model that describes the mass loss and fiber radius reduction kinetics during dissolution.

\section{Theory - dissolution kinetic models}

Different models are used for describing dissolution kinetics of various materials such as zero-order, first-order, advection/dispersion/reaction, GRAAL (Glass Reactivity with Allowance for the Alteration Levels), NoyesWhitney, Hixson-Crowell, Hopfenberg and KorsmeyerPeppas models, as well as similar in concept shrinking or contracting cylinder models [5,16,18-20]. Much of the confusion related to the modelling of degradation of glass fibers is due to the fact that dissolution is not the only process involved in degradation. The discrepancies between models are, however, mostly dominant in the short-term [5]. The whole degradation versus time curve is not linear as long as the complex processes take place. The model reported in this work is similar in concept to an existing solid-state model called the contracting cylinder [20] or shrinking cylinder [16], which relates the evolution of conversion to time. However, the novel model presented in this work differentiates between the complex shortterm and dissolution-dominated long-term processes. Furthermore, the novel model describes both dissolution and radius reduction kinetics without the necessity for introducing additional terms such as a conversion factor. Rate constants are often given in relation to the surface area of a material, thus describing dissolution behaviour from a unit of the material's surface area [14]. Surface area-based constants are used throughout this work.

\section{Experimental}

\subsection{Materials}

Boron-free and fluorine-free HiPer-tex W2020 glass fiber (GF) bundles were used. These are classified as high strength, high modulus R-glass (defined by an international standard [21]). The density is $2.54 \mathrm{~g} / \mathrm{cm}^{3}$; the mean filament diameter is $17 \pm 2 \mu \mathrm{m}$ [22].

Deionized water $(0.5-1.0 \mathrm{M} \Omega \cdot \mathrm{cm})$ was used for conditioning of the glass fibers. It was produced by using the water purification system Aquatron A4000 (Cole-Parmer, USA). The $\mathrm{pH}$ of the deionized water was determined to be 5.65 , which is lower than neutral due to dissolved $\mathrm{CO}_{2}$ (in equilibrium).

\subsection{Determination of number of fibers in the sample}

The amount of fibers is denoted as $n$. The length of fibers is $l=0.1 \mathrm{~m}$; the initial mass of a fiber bundle is $m_{0}=5.8 \mathrm{~g}$; the mean initial radius is $r_{0}=8.5 \bullet 10^{-6} \mathrm{~m}$. The amount of fibers was calculated using Equation 1:

$$
n=\frac{m_{0}}{\rho_{\text {glass }} \pi l r_{0}^{2}}
$$


The amount of fibers in the sample $n$ was determined to be 100602.

\subsection{Determination of surface area of the sample}

Since a surface reaction is of interest, it is important to identify the specific surface area of the glass material. The external surface area of glass fibers was evaluated from geometrical considerations as a product of number, circumference and length of fibers. The specific surface area of a studied sample can be calculated using Equation 2:

$$
S_{0}^{\text {specific }}=\frac{S_{0}}{m_{0}}=\frac{2 \pi n l r_{0}}{m_{0}}
$$

Specific surface area $S_{0}^{\text {specific }}$ was determined to be 0.09 $\left(\mathrm{m}^{2} / \mathrm{g}\right)$.

\subsection{Dissolution experiments}

Dissolution in water experiments of glass fibers were conducted using a batch system. Basically, infinite water availablity conditions were ensured by using fresh deionized water for each separate measurement. The ion release with time (dissolution) was obtained as the cumulative result of the individual ion release measurements.

The dissolution of ions was accelerated by conditioning the fibers at an elevated temperature of $60{ }^{\circ} \mathrm{C}$, since the dissolution reaction is an exothermic reaction $[5,6,18]$. The temperature of $60^{\circ} \mathrm{C}$ is often used for conditioning fiber-reinforced composites, and this fact provided an additional justification for choosing this particular temperature. The water's temperature was controlled via PID-controlled heating, giving an accuracy of $\pm 1^{\circ} \mathrm{C}$. Two-stage heating system was used in order to ensure that there is no contact of the sample water with other potential ion release sources, such as the heating element itself.

Samples were weighed using analytical scales AG204 ( $\pm 0.1 \mathrm{mg}$; Mettler Toledo, USA) before the experiments. Experiments were performed with 3 parallels.

The concentration of the dissolved ions in the water bach was measured by high resolution inductively coupled plasma mass spectrometry (HR-ICP-MS). Analyses were performed using a double focusing magnetic sector field ICP-MS Finnigan ELEMENT 2 (Thermo-Scientific), equipped with a sample introduction system PrepFAST (ESI/Elemental Scientific) and a pretreatment/digestion UltraClave (Milestone). Acidification of samples was performed using ultra-pure grade $\mathrm{HNO}_{3}$ SubPur (Milestone) to avoid adsorption of ions to the wall of the sample vials.

The benefit of HR-ICP-MS versus gravimetric analysis is that the model can be applied to obtain the rate constant $\left(K_{0}\right)$ of each ion separately, as well as for the total mass loss $\left(m_{\text {dissolved }}\right)$. The data obtained from the HR-ICP-MS experiments are in the form of mass concentration at each time point (non-cumulative) $c(\mathrm{~g} / \mathrm{L})$ and need to be converted to the $m_{\text {dissolved }}$ form by using Equation 3:

$$
m_{\text {dissolved }}=V_{\text {water }} \int_{0}^{t} c d t
$$

where $V_{\text {water }}$ is the volume of a water sample in the HR-ICPMS measurement. $V_{\text {water }}$ used for experiments was $50 \mathrm{~mL}$. Equation 3 is valid for each individual ion release and for the total mass loss.

\subsection{Radius reduction measurements.}

R-glass fibers were immersed in deionized water for prolonged periods of time, carefully dried with a paper tissue, and the fiber diameter was measured using a digital microscope RH-2000 (Hirox, Japan). The radii of around five fibers were measured at each time, and for each fiber, measurements of radii were made at three different locations, similarly as was done in another work [16].

Ethical approval: The conducted research is not related to either human or animal use.

\section{Results and Discussion}

\subsection{Elements released and respective chemical reactions}

The HR-ICP-MS method identified the following elements as being released during glass fiber degradation in deionized water: $\mathrm{Na}, \mathrm{K}, \mathrm{Ca}, \mathrm{Mg}, \mathrm{Fe}, \mathrm{Al}, \mathrm{Si}$, Cl. Release of B and $\mathrm{Zn}$ was found to be insignificant at less than $0.8 \mathrm{ppm}$, if the elements were present at all. 


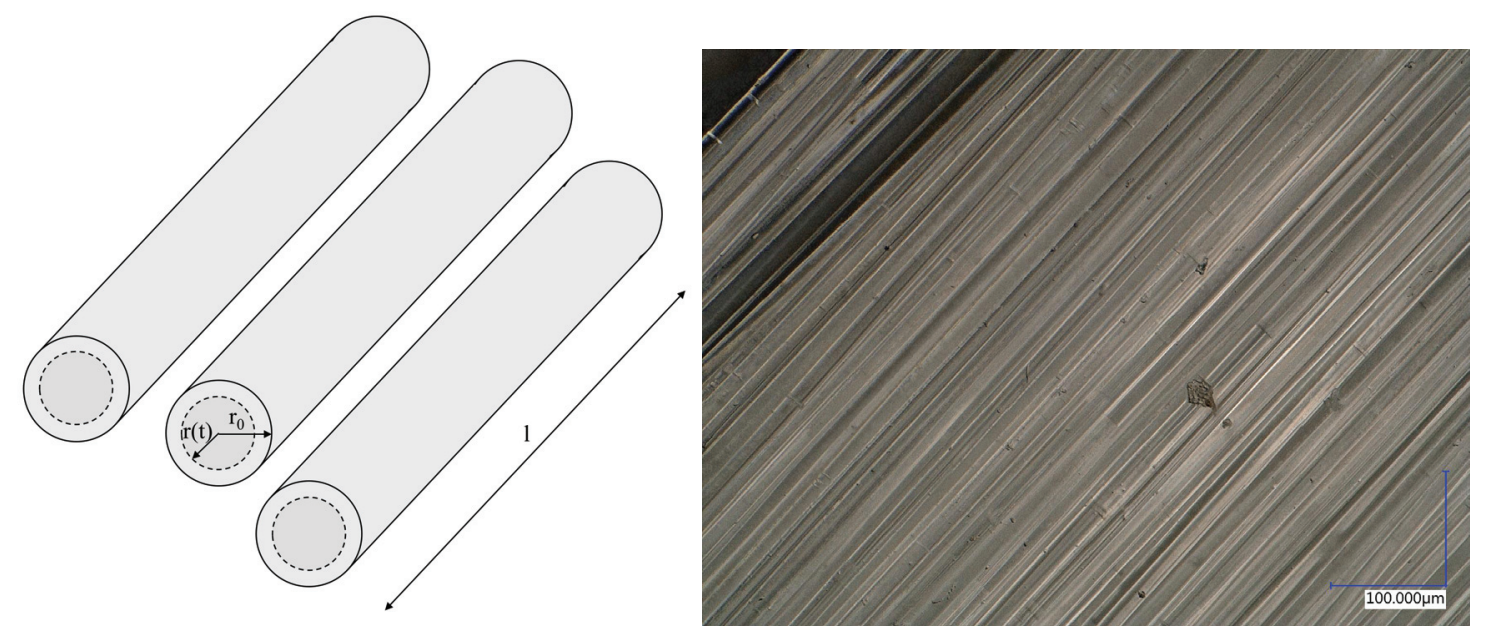

Figure 1: Left: Schematic representation of a fiber bundle and geometrical dimensions. Right: micrograph of a fiber bundle.

Chemical reactions involved in the degradation of the studied glass fibers for the identified released elements are shown in Chemical reactions (a)-(1) $[5,18,23]$ :

$$
\begin{gathered}
(\equiv \mathrm{Si}-\mathrm{ONa})+\mathrm{H}_{2} \mathrm{O} \rightarrow(\equiv \mathrm{Si}-\mathrm{OH})+\mathrm{OH}^{-}+\mathrm{Na}^{+} \\
(\equiv \mathrm{Si}-\mathrm{OK})+\mathrm{H}_{2} \mathrm{O} \rightarrow(\equiv \mathrm{Si}-\mathrm{OH})+\mathrm{OH}^{-}+\mathrm{K}^{+} \\
(\equiv \mathrm{Si}-\mathrm{O})_{2} \mathrm{Ca}+\mathrm{H}_{2} \mathrm{O} \rightarrow 2(\equiv \mathrm{Si}-\mathrm{OH})+2 \mathrm{OH}^{-}+\mathrm{Ca}^{2+} \\
(\equiv \mathrm{Si}-\mathrm{O})_{2} \mathrm{Mg}+\mathrm{H}_{2} \mathrm{O} \rightarrow 2(\equiv \mathrm{Si}-\mathrm{OH})+2 \mathrm{OH}^{-}+\mathrm{Mg}^{2+} \\
(\equiv \mathrm{Si}-\mathrm{O}-\mathrm{Al}=)+\mathrm{H}_{2} \mathrm{O} \leftrightarrow(\equiv \mathrm{Si}-\mathrm{OH})+(=\mathrm{Al}-\mathrm{OH}) \\
(\equiv \mathrm{Si}-\mathrm{O})_{2} \mathrm{Fe}+\mathrm{H}_{2} \mathrm{O} \rightarrow 2(\equiv \mathrm{Si}-\mathrm{OH})+2 \mathrm{OH}^{-}+\mathrm{Fe}^{2+} \\
(\equiv \mathrm{Si}-\mathrm{O})_{3} \mathrm{Fe}+\mathrm{H}_{2} \mathrm{O} \rightarrow 3(\equiv \mathrm{Si}-\mathrm{OH})+3 \mathrm{OH}^{-}+\mathrm{Fe}^{3+} \\
(\equiv \mathrm{Si}-\mathrm{O}-\mathrm{Si} \equiv)+\mathrm{OH}^{-} \leftrightarrow(\equiv \mathrm{Si}-\mathrm{OH})+\left(\equiv \mathrm{Si}-\mathrm{O}^{-}\right) \\
\quad\left(\equiv \mathrm{Si}-\mathrm{O}^{-}\right)+\mathrm{H}_{2} \mathrm{O} \leftrightarrow(\equiv \mathrm{Si}-\mathrm{OH})+O \mathrm{H}^{-}
\end{gathered}
$$

Combining chemical reactions (h) and (i), a summary reaction can be written as Chemical reaction (j):

$$
\begin{gathered}
(\equiv \mathrm{Si}-\mathrm{O}-\mathrm{Si} \equiv)+\mathrm{H}_{2} \mathrm{O} \leftrightarrow 2(\equiv \mathrm{Si}-\mathrm{OH}) \\
\mathrm{SiO}_{2}+2 \mathrm{H}_{2} \mathrm{O} \rightarrow \mathrm{H}_{4} \mathrm{SiO}_{4} \\
\mathrm{MeCl}_{x} \stackrel{\mathrm{H}_{2} \mathrm{O}}{\longrightarrow}\left(\mathrm{Me}^{x+}\right)+x \mathrm{Cl}^{-}
\end{gathered}
$$

\subsection{Zero-order kinetic model of a dissolving cylinder}

A schematic representation of a fiber bundle and important dimensions for the model are shown in Figure 1.
The number of fibers is $n(-)$; the initial radius of the fibers is $r_{0}(\mathrm{~m})$; the length of fibers is $l(\mathrm{~m})$.

The model involves the following assumptions. As a simplification, this model is deterministic and all fibers are assumed to have the same initial radius, which is $r_{0}$; and the cross-sectional surface area at the end of the fibres is assumed to be negligible in calculations of the surface area. The length of the long fibers $l$ is assumed to be constant during the whole dissolution process. During the whole degradation process, the density of the glass material stays constant $\left(\rho_{\text {glass }}\right)$.

Dissolution is a surface reaction. In a general case, the rate of the dissolution is dependent on the constant describing the rate of the reaction $\left(K_{0}\right)$, the glass surface area exposed to water $(S)$, the availability of water $\left(C_{\mathrm{H}_{2} \mathrm{O}}\right)$ and the order of the reaction $\left(n_{\text {reaction }}\right)$. The global model (general case) can then be mathematically expressed as Equation 4.

$$
\frac{\partial m}{\partial t}=K_{0} S C_{H_{2} O}^{n_{\text {reaction }}}
$$

In case of infinite availability of water, the rate of reaction becomes independent of the reactant (water) concentration, and the reaction order $n_{\text {reaction }}$ becomes 0 . In infinite water availability conditions, the surface reaction can be well-described with zero-order kinetics $[16,24]$, which can then be represented by a differential Equation 5:

$$
\frac{\partial m}{\partial t}=K_{0} S
$$


where $m(\mathrm{~g})$ is a total cumulative mass dissolved after time $t(\mathrm{~s}), K_{0}\left(\mathrm{~g} / \mathrm{m}^{2} \bullet \mathrm{s}\right)$ is a zero-order reaction kinetic constant and $S\left(\mathrm{~m}^{2}\right)$ is the glass surface area in contact with water.

As the reaction proceeds, the radius of the fibers is reduced and the total surface area $(S)$ is decreased, thus leading to a decrease in the rate of mass loss as seen in Equation 5. The overall ion release rate decreases proportionally to the decrease in total surface area or a decrease in fiber radius.

$$
\frac{S(t)}{S_{0}}=\frac{2 \pi n l r(t)}{2 \pi n l r_{0}}=\frac{r(t)}{r_{0}}
$$

It can be seen that $\frac{S(t)}{S_{0}}=\frac{r(t)}{r_{0}}$. Thus, the ion release rate decelerates linearly with a decrease in fiber radius. The mass loss has to slow down as the available surface area is reduced. Thus, the cumulative mass loss kinetic curve deviates from a linear dissolution.

The volume of a single fiber is $\pi r^{2} l$, where $l$ is the cylinder length and $r$ is the cylinder radius. For $n$ fibers, the volume is $\pi r^{2} l$ and mass is $\rho_{\text {glass }} n \pi r^{2} l$. The surface area of a single fiber is $2 n \pi r l$. For $n$ fibers it is $2 n \pi r l$. Substituting mass and surface area expressed in such terms into Equation 5,

$$
\begin{gathered}
\frac{\partial \rho_{\text {glass }} n \pi r^{2} l}{\partial t}=K_{0} \cdot 2 n \pi r l \\
\frac{\partial r^{2}}{\partial t}=\frac{2 K_{0}}{\rho_{\text {glass }}} r
\end{gathered}
$$

Substituting then $r^{2}$ with the following $z=r^{2}$,

$$
\frac{\partial z}{\partial t}=\frac{2 K_{0}}{\rho_{\text {glass }}} \sqrt{z}
$$

where $\frac{2 K_{0}}{\rho_{\text {glass }}}$ is a constant. Dividing both sides by $\sqrt{z}$,

$$
\frac{\frac{\partial z}{\partial t}}{\sqrt{z}}=\frac{2 K_{0}}{\rho_{\text {glass }}}
$$

Both sides are then integrated with respect to $t$,

$$
\int \frac{\frac{\partial z}{\partial t}}{\sqrt{z}} d t=\int \frac{2 K_{0}}{\rho_{\text {glass }}} d t
$$

$$
\begin{gathered}
\sqrt{z}=\frac{1}{2}\left(\frac{2 K_{0}}{\rho_{\text {glass }}} t+c^{\prime}\right) \\
\sqrt{z}=\frac{K_{0}}{\rho_{\text {glass }}} t+c^{\prime \prime}
\end{gathered}
$$

where $c$ ' and $c$ " are arbitrary constants after integration. Substituting $r^{2}$ back into the equation:

$$
\begin{gathered}
\sqrt{r^{2}}=\frac{K_{0}}{\rho_{\text {glass }}} t+c^{\prime \prime} \\
\pm r=\frac{K_{0}}{\rho_{\text {glass }}} t+c^{\prime \prime}
\end{gathered}
$$

It can be seen that the radius reduction is linear with time, where the proportionality is given by the zero-order kinetic constant $K_{0}\left(\mathrm{~g} / \mathrm{m}^{2} \bullet \mathrm{s}\right)$ and the density of the glass $\left(\mathrm{g} / \mathrm{m}^{3}\right)$. A linear radius reduction of fibers with time was previously experimentally observed in another work [16]. Since the radius reduction depends on the initial radius $r_{0}$ of the fibers $(m)$, the arbitrary constant $c$ " $(m)$ is equal to the initial radius.

The kinetic model equation for fiber radius reduction then becomes as shown in Equation 16:

$$
r=r_{0}-\frac{K_{0}}{\rho_{\text {glass }}} t
$$

Returning to the mass loss kinetics (Equation 5),

$$
\frac{\partial m}{\partial t}=K_{0} S=K_{0} \cdot 2 n \pi r l
$$

Substituting $r$ for the radius reduction kinetic Equation 28, the final mass loss kinetic model equation in differential form is obtained (Equation 17):

$$
\frac{\partial m}{\partial t}=2 n \pi l\left(r_{0} K_{0}-\frac{K_{0}^{2}}{\rho_{\text {glass }}} t\right)
$$

Integrating the obtained Equation 17 over time $t$, the integral model equation is obtained, describing the cumulative mass loss (ion release):

$$
m_{\text {dissolved }}=\int_{0}^{t} 2 n \pi l\left(r_{0} K_{0}-\frac{K_{0}^{2}}{\rho_{\text {glass }}} t\right) d t
$$

Integrating and solving for $\sqrt{z}$, 


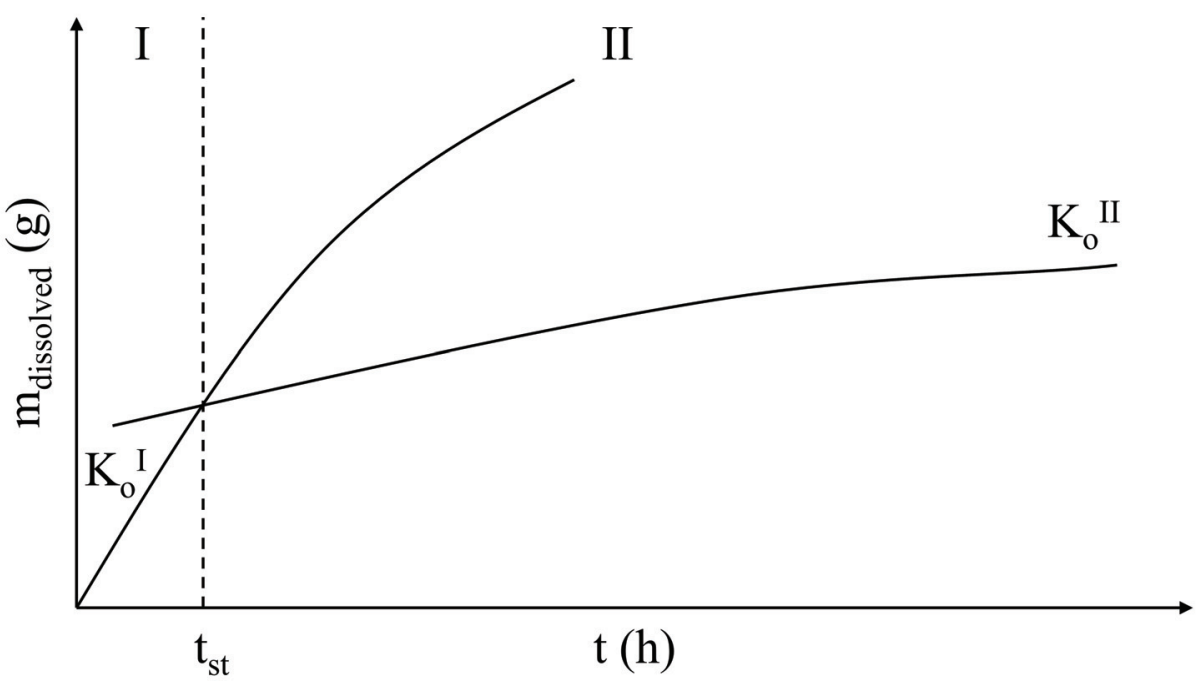

Figure 2: Separation of mass loss or cumulative ion release curves into (I) short-term non-steady-state and (II) long-term steady-state regions.

Definite integral solution is then the following (Equation 19):

$$
m_{\text {dissolved }}=-\frac{1}{2} \cdot 2 n \pi l \cdot t\left(\frac{K_{0}^{2}}{\rho_{\text {glass }}} t-2 r_{0} K_{0}\right)
$$

The final mass loss model kinetic equation in the integral form is then the following (Equation 20):

$$
m_{\text {dissolved }}=n \pi l\left(2 r_{0} K_{0} t-\frac{K_{0}^{2}}{\rho_{\text {glass }}} t^{2}\right)
$$

The solution of Equation 20 is then checked using an alternative approach. Based on the mass conservation principle, mass loss in integral form can be also written as Equation 21:

$$
m_{\text {dissolved }}=m_{0}-m=\rho_{\text {glass }} n \pi l\left(r_{0}^{2}-r^{2}\right)
$$

Combining Equations 16 and 21,

$$
\begin{aligned}
m_{\text {dissolved }}= & \rho_{\text {glass }} n \pi l\left(r_{0}^{2}-\left(r_{0}-\frac{K_{0}}{\rho_{\text {glass }}} t\right)^{2}\right)= \\
= & n \pi l\left(2 r_{0} K_{0} t-\frac{K_{0}^{2}}{\rho_{\text {glass }}} t^{2}\right)
\end{aligned}
$$

The obtained Equation 22 is the same mass loss kinetic equation in the integral form as Equation 20. The use of two alternative mathematical ways to obtain
Equations 20 and 22 by the integration and by the mass conservation principle, respectively, has proven the mathematical consistency of the model. The fact that the model is adequate and physical was demonstrated by its ability to explain the experimentally observed dissolution phenomena as described later.

\subsection{The model extended to short-term and long-term degradation.}

The reaction kinetics described above apply for a dissolution-dominated process. As shown in the Chemical reactions (a)-(l), various competing reactions happen simultaneously. Initially these reactions happen at independent rates, later one process becomes limiting and dominates the behaviour. Therefore, the degradation process should be divided into a short-term non-steadystate process and a long-term steady-state process since the subprocesses involved follow individual kinetics and are likely interdependent contributing to the complexity of the short-term region. In the non-steady-state region the process is rather complex, involving in addition to dissolution also other competing leaching mechanisms such as ion exchange and gel formation, and thus cannot be properly described with only one kinetic equation $[5,18]$. The complexity and varying rates of the competing processes in the short-term make this stage of the degradation to be non-linear non-steady-state. In the long-term hygrothermal degradation of glass fibers, however, dissolution kinetics become dominant $[5,18]$ and the process becomes then steady-state following the 
Table 1: Model parameters and fit to experimental data (total mass loss $m_{\text {dissolved }}$ ).

\begin{tabular}{lllll}
\hline$K_{0}^{I}\left(\mathrm{~g} / \mathrm{m}^{2} \bullet \mathrm{s}\right)$ & $K_{0}^{I I}\left(\mathrm{~g} / \mathrm{m}^{2} \bullet \mathrm{s}\right)$ & $t_{s t}(\mathrm{~h})$ & $\begin{array}{l}\mathbf{R}^{2} \\
\left(\mathrm{t} \leq \mathrm{t}_{\mathrm{st}}\right)\end{array}$ & $\begin{array}{l}\mathbf{R}^{2} \\
\left(\mathrm{t}>\mathrm{t}_{\mathrm{st}}\right)\end{array}$ \\
\hline $3.00 \bullet 10^{-9}$ & $6.68 \bullet 10^{-10}$ & 166 & 0.8069 & 0.9653 \\
\hline
\end{tabular}

Table 2: Model parameters for individual released ions and fit to experimental data.

\begin{tabular}{lllll}
\hline & $K_{0}^{I}\left(\mathbf{g} / \mathrm{m}^{2} \bullet \mathbf{s}\right)$ & $K_{0}^{I I}\left(\mathbf{g} / \mathbf{m}^{2} \bullet \mathbf{s}\right)$ & $\begin{array}{l}\mathbf{R}^{2} \\
\left(\mathbf{t} \leq \mathbf{t}_{\mathrm{st}}\right)\end{array}$ & $\begin{array}{l}\mathbf{R}^{2} \\
\left(\mathbf{t}>\mathbf{t}_{\mathrm{st}}\right)\end{array}$ \\
\hline $\mathrm{Na}$ & $6.80 \cdot 10^{-11}$ & $1.80 \bullet 10^{-11}$ & 0.5326 & 0.9578 \\
$\mathrm{~K}$ & $4.85 \bullet 10^{-11}$ & $9.80 \cdot 10^{-12}$ & 0.5583 & 0.9211 \\
$\mathrm{Ca}$ & $8.72 \bullet 10^{-10}$ & $9.70 \bullet 10^{-11}$ & 0.7256 & 0.9310 \\
$\mathrm{Mg}$ & $4.85 \bullet 10^{-10}$ & $1.02 \bullet 10^{-10}$ & 0.7164 & 0.9898 \\
$\mathrm{Fe}$ & $2.20 \bullet 10^{-12}$ & $4.40 \cdot 10^{-13}$ & 0.9261 & 0.8963 \\
$\mathrm{Al}$ & $1.45 \bullet 10^{-10}$ & $4.68 \cdot 10^{-11}$ & 0.7596 & 0.9272 \\
$\mathrm{Si}$ & $1.10 \bullet 10^{-9}$ & $3.80 \bullet 10^{-10}$ & 0.9177 & 0.9781 \\
$\mathrm{Cl}$ & $7.80 \bullet 10^{-11}$ & $2.28 \cdot 10^{-11}$ & 0.6605 & 0.9572 \\
\hline
\end{tabular}

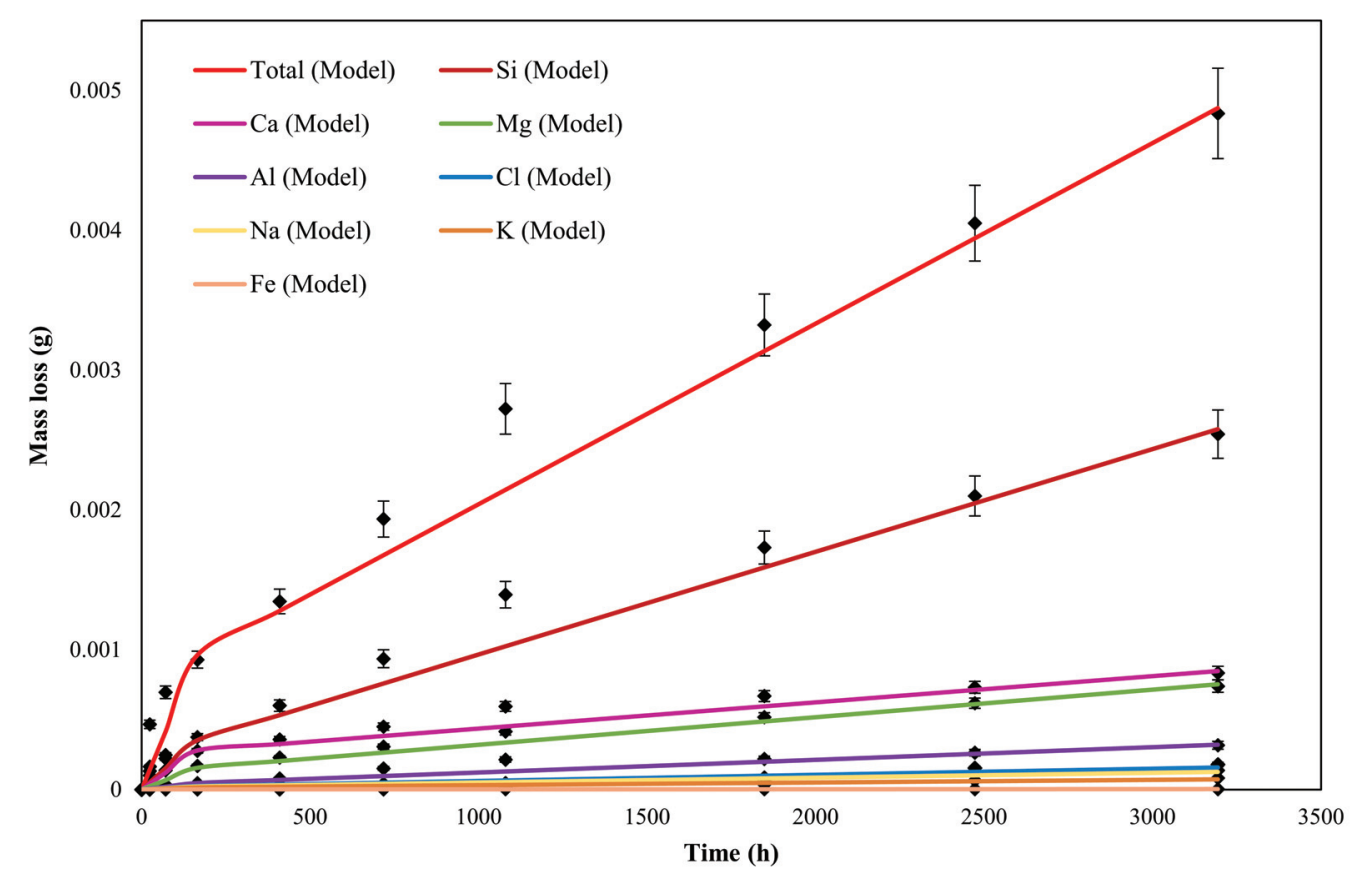

Figure 3: Experimental data and predicted ion release and total mass loss kinetics.

zero-order kinetics. In the long-term degradation, kinetic equations described above become physical.

When long-term degradation is of most interest, such as in this work, the shape of the non-linear short-term part is not important, an approximate solution can then be used to describe also the short-term non-steady-state stage with dissolving cylinder zero-order kinetic model. In case when short-term degradation is of most importance, kinetic models for each individual subprocesses (dissolution, ion exchange, gel formation) taking place in the short-term non-steady-state should be studied and implemented, and their influence on each other should be understood.

The fiber radius decreases at a constant rate (linearly) in time. However, the induction period before the linear regime is often observed [16], which can be explained with the complexity of the short-term non-steady-state process and, to the best knowledge of the authors, was not explained before. 


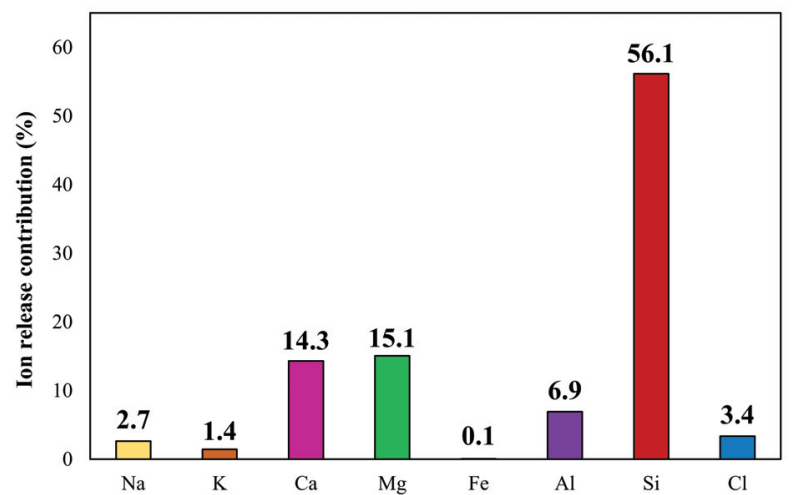

Figure 4: Comparison of ion release rates in the steady-state (values have been calculated from the rate constants in the steady-state)

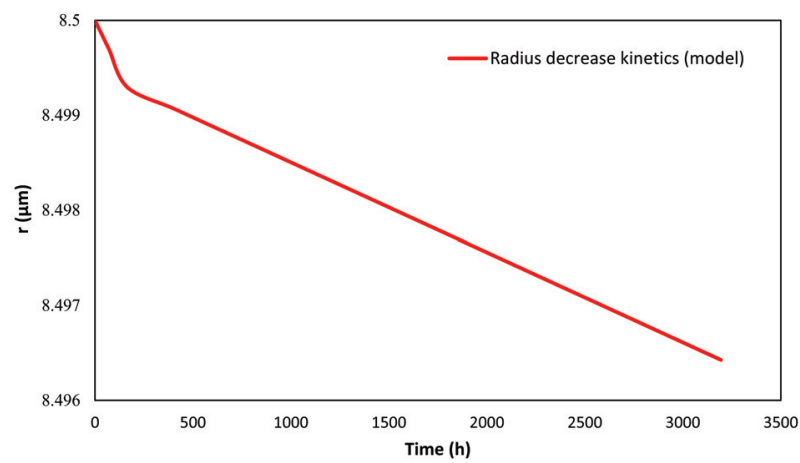

Figure 5: Modelled radius reduction in R-glass fibers after treatment in water at various times at $60^{\circ} \mathrm{C}$.

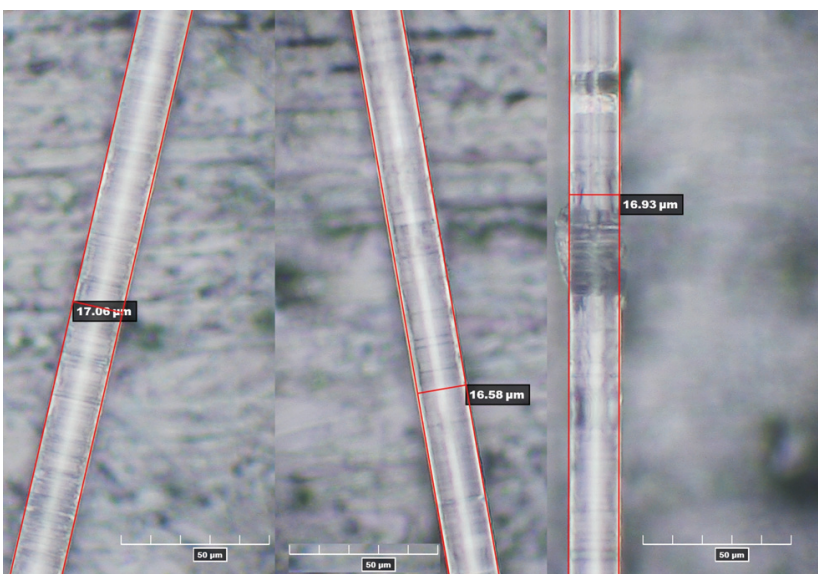

Figure 6: Digital microscope images of R-glass fibers from left to right: untreated; after $69 \mathrm{~h}$ in water at $60^{\circ} \mathrm{C}$; after $3194 \mathrm{~h}$ in water at $60^{\circ} \mathrm{C}$.

The whole process can be divided into two regions as shown in Figure 2 and can be described via four parameters: $r_{0}, t_{s t}, K_{0}^{I}, K_{0}^{I I}$.
Table 3: Predicted dissolution times for various mass and radius loss values at $60^{\circ} \mathrm{C}$.

\begin{tabular}{lll}
\hline $\begin{array}{l}\text { Time in water } \\
\text { (years) }\end{array}$ & Mass loss (\%) & Radius loss (\%) \\
\hline 0.5 & 0.10 & 0.05 \\
2.5 & 0.50 & 0.25 \\
5.1 & 1.00 & 0.50 \\
25.9 & 5.00 & 2.53 \\
52.5 & 10.00 & 5.13 \\
300.2 & 50.00 & 29.30 \\
512.6 & 75.00 & 50.02 \\
1025.1 & 100.00 & 100.00 \\
\hline
\end{tabular}

The final model equations combining approximated non-steady-state short-term and physically-correct steadystate long-term dissolution kinetics are proposed.

The radius reduction kinetic model based on Equation 16 is shown in Equation 23:

$$
\left\{\begin{array}{c}
t \leq t_{s t}: \quad r=r_{0}-\frac{K_{0}^{I}}{\rho_{\text {glass }}} t \\
t>t_{s t}: \quad r=r_{t_{s t}}-\frac{K_{0}^{I I}}{\rho_{\text {glass }}}\left(t-t_{s t}\right)
\end{array}\right.
$$

The mass loss kinetic model based on Equation 20 is shown in Equation 24:

$$
\left\{\begin{array}{c}
t \leq t_{s t}: m_{\text {dissolved }}=n \pi l\left(2 r_{0} K_{0}^{I} t-\frac{K_{0}^{I}{ }^{2}}{\rho_{\text {glass }}} t^{2}\right) \\
t>t_{\text {st }}: \quad m_{\text {dissolved }}=m_{\text {dissolved }_{t s t}}+n \pi l\left(2 r_{t_{s t}} K_{0}^{I I}\left(t-t_{s t}\right)-\frac{K_{0}^{I I 2}}{\rho_{\text {glass }}}\left(t-t_{s t}\right)^{2}\right)
\end{array}\right.
$$

where $K_{0}^{I}$ and $K_{0}^{I I}$ are the rate constants $\left(\mathrm{g} / \mathrm{m}^{2} \bullet \mathrm{s}\right)$ for the short-term non-steady-state and long-term steady-state regions, respectively; $r_{t s t}(\mathrm{~m})$ and $m_{\text {dissolved }} t_{s t}(\mathrm{~g})$ are the fiber radius and lost mass after time $t_{s t}(\mathrm{~s})$, when steadystate is reached.

\subsection{Dissolution of R-glass fibers explained with the model}

Experimentally $m_{\text {dissolved }}$ was measured as a sum of all ions' release quantified with HR-ICP-MS cumulatively over time. Alternatively, a gravimetric analysis over time can be used to obtain $m_{\text {dissolved }}$. Both kinetic parameters $K_{0}^{I}$ and $K_{0}^{I I}$ are determined from obtained $m_{\text {dissolved }}-t$ curves by using the 
described methodology in this work for each individual element, as well as for the total mass loss.

Ions released from the studied glass material are the following: $\mathrm{Na}, \mathrm{K}, \mathrm{Ca}, \mathrm{Mg}, \mathrm{Fe}, \mathrm{Al}, \mathrm{Si}, \mathrm{Cl}$. The total mass of all ions released is the cumulative mass loss, as shown by Equation 25:

$$
\begin{gathered}
m_{\text {dissolved }}=m_{\text {dissolved }_{N a}}+m_{\text {dissolved }_{K}}+m_{\text {dissolved }_{C a}}+m_{\text {dissolved }_{M g}}+m_{\text {dissolved }_{F e}} \\
+m_{\text {dissolved }_{A l}}+m_{\text {dissolved }_{S i}}+m_{\text {dissolved }_{C l}}
\end{gathered}
$$

The total mass loss is described by four parameters $\left(r_{0}, t_{s t}, K_{0}^{I}, K_{0}^{I I}\right)$. For each ion, individual $K_{0}^{I}$ and $K_{0}^{I I}$ values have to be obtained, while $t_{s t}$ and $r_{0}$ for each individual ion release are the same and are equivalent to that for the total mass loss.

From the cumulative data of ions released altogether $\left(m_{\text {dissolved }}\right)$, the kinetic model parameters $\left(K_{0}^{I}\right.$ and $\left.K_{0}^{I I}\right)$ were obtained using non-linear regression for each separate ion as well as for the total mass loss curve. The Generalized Reduced Gradient (GRG) non-linear regression method was used by minimizing the sum of squares of the differences between modelled and experimental values. The obtained parameters and model fit to experimental data are systematized in Table 1. Obtained values are reasonable (similar order of magnitude) compared with dissolution rates of other glass fibers studied in literature [25].

Using the obtained $t_{s t}$, these parameters are included in the model for each individual ion release $(\mathrm{Na}, \mathrm{K}, \mathrm{Ca}$, $\mathrm{Mg}, \mathrm{Fe}, \mathrm{Al}, \mathrm{Si}, \mathrm{Cl}) . K_{0}^{I}$ and $K_{0}^{I I}$ are obtained for each ion by regression of experimental data for each individual ion cumulative release curve. The same method of non-linear regression as described above was used in each case. The rate constants $K_{0}^{I}$ and $K_{0}^{I I}$ for the identified released ions are systematized in Table 2. It should be noted that the $\mathrm{R}^{2}$ values in the non-steady-state $\left(\mathrm{t} \leq \mathrm{t}_{\mathrm{s}}\right)$ are fairly low, while the fit is good in the steady-state region $\left(t>t_{s t}\right)$. As was mentioned earlier, this is because the model can only be used as a mathematical approximation in the non-steadystate, while it is physical in the steady-state long-term.

Experimental data and modelled curves for individual ion release and total mass loss are shown in Figure 3. Experimentally mass loss was obtained from HR-ICP-MS measurements for separate ions being released.

Rates of ion release during steady-state for the studied material are compared in Figure 4.

The contribution from Si to the total mass loss is the largest ( $56.1 \%$ by mass) and seems to govern the dissolution process. $\mathrm{Ca}$ and $\mathrm{Mg}$ are released at approximately similar rates to each other and contribute 14.3 and $15.1 \%$ to the total mass loss, respectively, while all other elements contribute less than $7 \%$ individually. Once the steadystate is reached, it can be assumed that the reactions do not have any effect on each other and proceed at constant independent rates. It can be speculated that in the steadystate some equilibrium composition of glass (different from the bulk composition) is obtained in the outer layers that are contact with water, allowing elements to dissolve at some limiting rate and proportionally to their content in the outer layers of the glass.

Radius reduction in R-glass fibers after treatment in water at various times at $60^{\circ} \mathrm{C}$ predicted with the model is shown in Figure 5. The fiber radius decrease could not be captured with a digital microscope. Digital micrographs of fibers, untreated and treated in water are shown in Figure 6.

The lack of accuracy is reasonable, taking into account that the radius reduction predicted by the model in $3194 \mathrm{~h}$ time is only $0.0036 \mu \mathrm{m}$ ( $0.04 \%$ radius loss) as seen in Figure 5, and the microscope resolution is $0.16 \mu \mathrm{m}$. Furthermore, a statistical error has to be considered since the radius is not perfectly equal in different locations of the fibers (as seen by discrepancy in measurements reported in Figure 6).

With the reaction rates obtained in this work, the full dissolution of the studied R-glass fibers would take $8.98 \cdot 10^{6} \mathrm{~h}$ or 1025.1 years as reported in Table 3. The radius loss after 25 years, a typical design lifetime, would be $2.45 \%$. These values are for $60^{\circ} \mathrm{C}$. For lower temperatures, the radius reduction would be even less [5,6,18]. The effect of temperature on dissolution kinetics and the effect of cracks in the fibers of this particular glass material will be studied in the future.

\section{Conclusions}

In this study, the long-term (3194 h) dissolution of R-glass fibers in water was studied experimentally. A dissolving cylinder zero-order kinetic model was developed and successfully used to describe the kinetics of mass loss and the fiber's radius reduction during dissolution in water.

Elements released during degradation were determined to be $\mathrm{Na}, \mathrm{K}, \mathrm{Ca}, \mathrm{Mg}, \mathrm{Fe}, \mathrm{Al}, \mathrm{Si}$ and $\mathrm{Cl}$. The total material loss and release of each separate ion was modelled using the developed kinetic equations, and rate constants were obtained and reported. The contribution of $\mathrm{Si}$ to the total mass loss was the largest ( $56.1 \%$ by mass) and governed the dissolution process.

The model differentiates between the complex shortterm and dissolution-dominated long-term processes. 
Furthermore, the novelty of the model is the ability to describe both dissolution and radius reduction kinetics without the necessity for introducing additional terms such as a conversion factor. The model is able to predict both mass loss and radius reduction kinetics using the same four parameters, which can be determined experimentally. The methodology provided in this work offers the guidelines to obtain the required parameters to use the model in practice. The developed model is useful for both monitoring the radius of degrading fibers and for monitoring the time evolution of the loss of material.

The radius reduction was found to be linear with time during dissolution when a steady-state is reached. The zero-order kinetic constant and the density of the glass describe the rate (proportionality) of the dissolution. Radius reduction predicted by the model in $3194 \mathrm{~h}$ time was only $0.0036 \mu \mathrm{m}$ ( $0.04 \%$ radius loss) at $60^{\circ} \mathrm{C}$ and could not be captured with a microscope. The full dissolution of the studied R-glass fibers would take $8.98 \bullet 10^{6} \mathrm{~h}$ or 1025.1 years. The radius loss after 25 years, a typical design lifetime, would be $2.45 \%$.

Acknowledgments: This work is part of the DNV GL led Joint Industry Project "Affordable Composites" with twelve industrial partners and the Norwegian University of Science and Technology (NTNU). The authors would like to express their thanks for the financial support by The Research Council of Norway (Project 245606/E30 in the Petromaks 2 programme). The authors are thankful to Abedin I. Gagani, Syverin Lierhagen and Melanie Shebel. The first author is especially grateful to Oksana V. Golubova.

Conflict of interest: Authors declare no conflict of interest.

\section{References}

[1] Wallenberger F.T., Commercial and Experimental Glass Fibers, in: Fiberglass and Glass Technology, Eds: Wallenberger F.T., Bingham P.A., Springer, US, 2010.

[2] Steinmann W., Saelhoff A.-K., Essential Properties of Fibres for Composite Applications, in: Fibrous and Textile Materials for Composite Applications, Textile Science and Clothing Technology, Eds.: Rana S., Fangueiro R., Springer, Singapore, 2016.

[3] Tournié A., Ricciardi P., Colomban P., Glass Corrosion Mechanisms: A Multiscale Analysis, Solid State Ionics, 2008, 179(38), 2142-2154.

[4] Brown E.N., Davis A.K., Jonnalagadda K.D., Sottos N.R., Effect of surface treatment on the hydrolytic stability of E-glass fiber bundle tensile strength, Compos. Sci. Technol., 2005, 65, 129-136.

[5] Grambow B., Müller R., First-order dissolution rate law and the role of surface layers in glass performance assessment, J. Nucl. Mater., 2001, 298(1-2), 112-124.

[6] Grambow B., A General Rate Equation for Nuclear Waste Glass Corrosion, Mat. Res. Soc. Symp. Proc., 1985, 44, 15-27.

[7] Krauklis A.E., Gagani A.I., Echtermeyer A.T., Near-Infrared Spectroscopic Method for Monitoring Water Content in Epoxy Resins and Fiber-Reinforced Composites, Materials, 2018, 11(4), 586-599.

[8] Stamenović M.R., Putić S.S., Rakin M.B., Medjo B., Čikara D., Effect of alkaline and acidic solutions on the tensile properties of glass-polyester pipes, Mater. Des., 2011, 32(4), 2456-2461.

[9] Krauklis A.E., Echtermeyer A.T., Mechanism of Yellowing: Carbonyl Formation during Hygrothermal Aging in a Common Amine Epoxy, Polymers, 2018, 10(9), 1017-1031.

[10] Amaro A.M., Reis P.N.B., Neto M.A., Louro C., Effects of alkaline and acid solutions on glass/epoxy composites, Polym. Degrad. Stab., 2013, 98(4), 853-862.

[11] Delage F., Ghaleb D., Dussossoy J.L., Chevallier O., Vernaz E., A mechanistic model for understanding nuclear waste glass dissolution, J. Nucl. Mater., 1992, 190, 191-197.

[12] Geisler-Wierwille T., Nagel T.J., Kilburn M.R., Janssen A., Icenhower J., Fonseca R.O.C., Grange M.L., Nemchin A.A., The Mechanism of Borosilicate Glass Corrosion Revisited, Geochim. Cosmochim. Acta, 2015, 158, 112-129.

[13] Icenhower J., Steefel C.I., Dissolution Rate of Borosilicate Glass SON68: A Method of Quantification Based upon Interferometry and Implications for Experimental and Natural Weathering Rates of Glass, Geochim. Cosmochim. Acta, 2015, 157, 147-163.

[14] Ma T., Jivkov A.P., Li W., Liang W., Wang Y., Xu H., Han X., A mechanistic model for long-term nuclear waste glass dissolution integrating chemical affinity and interfacial diffusion barrier, J. Nucl. Mater., 2017, 486, 70-85.

[15] Mišíková L., Liška M., Galusková D., CORROSION OF E-GLASS FIBERS IN DISTILLED WATER, Ceram. Silikaty, 2007, 51(3), 131135.

[16] Bashir S.T., Yang L., Liggat J.J., Thomason J.L., Kinetics of dissolution of glass fibre in hot alkaline solution, J. Mater. Sci. 2018, 53(3), 1710-1722.

[17] Krauklis A.E., Echtermeyer A.T., Dissolving Cylinder Zero-Order Kinetic Model for Predicting Hygrothermal Aging of Glass Fiber Bundles and Fiber-Reinforced Composites, International Glass Fiber Symposium, 2018.

[18] Report RWM005105, AMEC/103498/02 Issue 2: Review of glass dissolution models and application to UK glasses, Didcot, 2015.

[19] Costa P., Sousa Lobo J.M., Review: Modeling and comparison of dissolution profiles, Eur. J. Pharm. Sci., 2001, 13, 123-133.

[20] Khawam A., Flanagan D.R., Solid-State Kinetic Models: Basics and Mathematical Fundamentals, J. Phys. Chem. B, 2006, 110, 17315-17328.

[21] International Standard ISO 2078:1993 (revised in 2014), Textile glass - Yarns - Designation, 2014.

[22] 3B Fibreglass technical data sheet. HiPer-tex W2020 rovings, Belgium, 2012.

[23] Li H., Gu P., Watson J., Meng J., Acid corrosion resistance and mechanism of E-glass fibers: boron factor, J. Mater. Sci., 2013, 48(8), 3075-3087. 
[24] Čornaja S., Fizikālā k̦īmija. Elektroḳīmija. Kinētika, RTU Izdevniecība, Rīga, 2008, (in Latvian).

[25] Eastes W., Potter R.M., Hadley J.G., Estimating in-vitro glass fiber dissolution rate from composition, Inhal. Toxicol., 2000, 12, 269-280. 